RESEARCH

\title{
Comparative Analysis of 1196 Orthologous Mouse and Human Full-length mRNA and Protein Sequences
}

\author{
Wojciech Makałowski, Jinghui Zhang, and Mark S. Boguski
}

\author{
National Center for Biotechnology Information, National Library of Medicine, National Institutes of \\ Health, Bethesda, Maryland 20894
}

A large set of mRNA and encoded protein sequences, from orthologous murine and human genes, was compiled to analyze statistical, biological, and evolutionary properties of coding and noncoding transcribed sequences. Protein sequence conservation varied between $36 \%$ and $100 \%$ identity, with an average value of $85 \%$. The average degree of nucleotide sequence identity for the corresponding coding sequences was also $\sim 85 \%$, whereas $5^{\prime}$ and $3^{\prime}$ untranslated regions (UTRs) were less conserved, with aligned identities of $67 \%$ and $69 \%$, respectively. For some mouse and human genes, nucleotide sequences are more highly conserved than the encoded protein sequences. A subset of 32 sequences, consisting of only mouse/human protein pairs for which the human sequence represents a positionally cloned disease gene, had properties very similar to the larger data set, suggesting that our data are representative of the genome as a whole. With respect to sequence conservation, two interesting outliers are the breast cancer (BRCAI) gene product and the testis-determining factor (SRY), both of which display among the lowest degrees of sequence identity. The occurrence of both introns and repetitive elements (e.g., Alu, Bl) in 5' and $3^{\prime}$ UTRs was also studied. These results provide one benchmark for the "comparative genomics" of mice and humans, with practical implications for the cross-referencing of transcript maps. Also, they should prove useful in estimating the additional sampling diversity provided by mouse EST sequencing projects designed to complement the existing human CDNA collection.

The assertion that a pair of sequences is "highly homologous" or "strongly conserved" without reference to any objective scale of measurement is seen often in the genomics and general molecular biology literature. Quantifying the degree of similarity is important in any context, but this is true especially in conjunction with the automated analysis systems that are being developed to annotate the 100 million bases of human genomic sequence data that are anticipated over the next 2 years. Surprisingly, in this community little attention has been paid to studying the range of sequence variation between orthologous genes and proteins in different organisms, or among paralogous members of gene families in a single organism. This situation is made more urgent by the existence of $>400,000$ human cDNA sequences, and an additional 400,000 mouse cDNA sequences that are expected over the next

'Corresponding author.

E-MAlL makalow@ncbi.nlm.nih.gov; FAX (301) 480-9241.
2 years (Washington University and Howard Hughes Medical Institute 1996)-there are already more than 50,000 mouse cDNAs in GenBank. Another important factor is the international effort to construct a transcript map of the human genome using gene-based reagents derived largely from cDNAs (Boguski and Schuler 1995) and the desirability of correlating this effort with a corresponding mouse gene map (M. Seldin and J. Nadeau, pers. comm.).

Much pioneering work has been done on the molecular evolution of mammalian genes (Nei 1987; Li and Graur 1991), and, as large portions of the mammalian genomic sequence become available during the next few years, many more biologists will be turning to these earlier studies as a foundation upon which to intrepret the new data. Perhaps most pertinent to the current study is the work of Wolfe and Sharp (1993), who studied the nucleotide sequence conservation of 363 mouse and rat gene pairs representing 411 kilobases of sequence data. The current study addresses the issue of orthologous sequence conser- 
vation between 1196 mouse and human genes representing 2239 kilobases of sequence data. We studied the range of sequence variations in the $5^{\prime}$ and $3^{\prime}$ untranslated regions (UTRs) as well as the coding sequences (CDSs) and proteins. We examined some of the biological properties of those sequence pairs with extreme values of sequence conservation or divergence. We also analyzed sequence features such as the presence of introns and repetitive elements in mRNA untranslated regions, an issue of practical importance for anyone designing gene-specific sequence tagged sites (STSs) for use in mapping (Boguski and Schuler 1995). Our analyses yielded some surprising results that, upon further evaluation, are consistent with previous studies on the molecular evolution of rodents and humans. These findings are discussed in the context of interpreting human genomic and mouse cDNA sequences and also in terms of their implications for cross-referencing transcript maps of the mouse and human genomes.

\section{RESULTS AND DISCUSSION}

Nucleotide and protein sequences were aligned
A

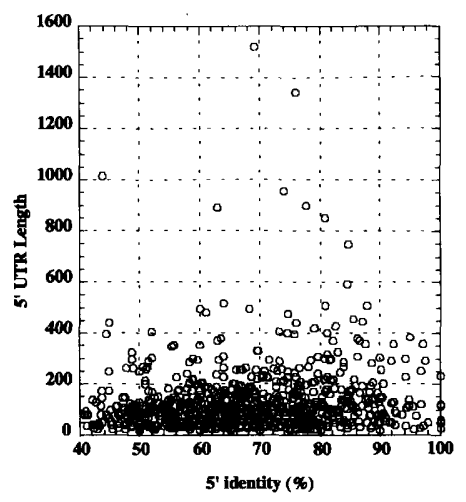

C

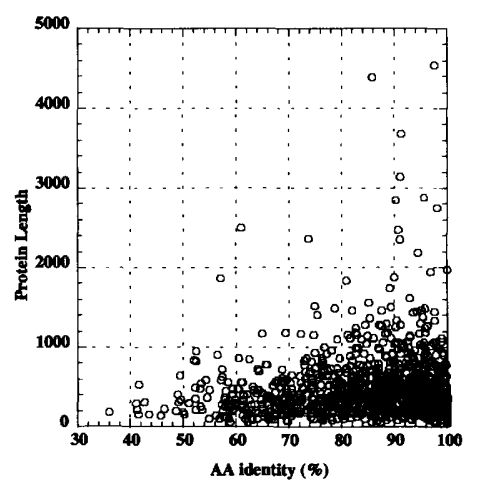

B

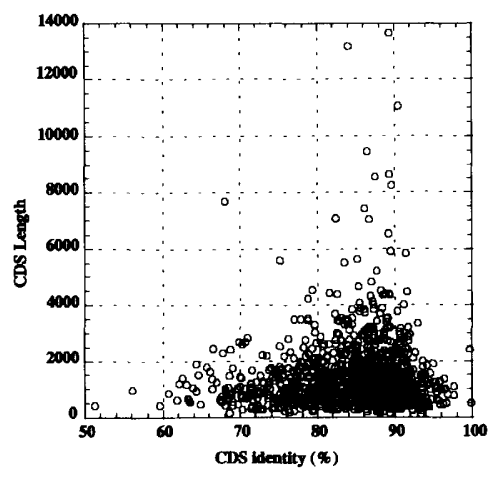

D

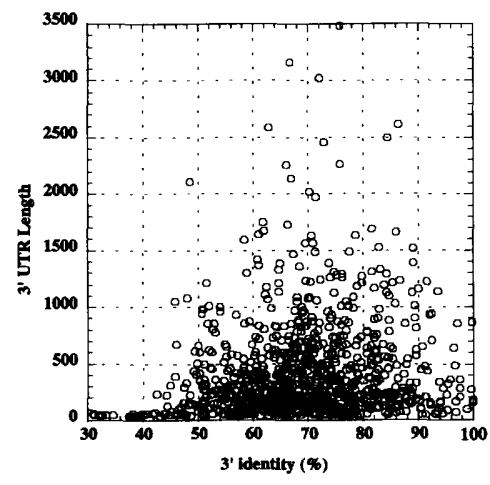

Figure 1 Scatter plots of sequence alignment length vs. sequence conservation. $(A, B, D)$ Aligned nucleotide sequence identity on the $x$-axis. (C) Aligned protein (AA) sequence identity. as described in Methods. All results refer to aligned sequence pairs, excluding gaps. A table containing alignment length and sequence conservation for all 1196 mRNA and protein pairs is available as an electronic supplement on the World Wide Web at http://www.cshl.org. (Follow the links to this issue of the journal.)

\section{Statistical Properties of the Data}

The 878 5' UTR sequences consisted of 108,955 nucleotides. Alignment lengths ranged in size from 20 to 1521 nucleotides with a mean value of 124 nucleotides (standard deviation, SD = 127). These lengths were distributed narrowly, with $50 \%$ of the values in the range of $50-147$ nucleotides; $90 \%$ of the values were $<250$ nucleotides (Fig. 1A). The $9473^{\prime}$ UTR sequences consisted of 397,040 nucleotides with alignment lengths of 40-3478 nucleotides. The mean and SD were 414 and 426 nucleotides, respectively. The $3^{\prime}$ UTR lengths were distributed somewhat more broadly than the $5^{\prime}$ UTR lengths, with $50 \%$ of the values between 133-558 nucleotides; $90 \%$ of the values were $<942$ nucleotides (Fig. 1D). Nevertheless, in both cases a number of outlying values are apparent. For example, the two longest $5^{\prime}$ UTRs are those of mouse beta-2adrenergic receptor (2211 bases; GenBank accession no. X15643) and a human growth/differentiation factor (1346 bases; GenBank accession no. M62302). For 3 ' UTRs, the longest were those of the human tissue inhibitor of metalloproteinase-3 (3663 bases; GenBank accession no. U14394), the human recombination-activating protein RAG-1 (3301 bases; GenBank accession no. M29474), and a human stem-cell leukemia gene product (3427 bases; GenBank accession no. M61108). On average, 3' UTR alignments were 3.34 times longer than $5^{\prime}$ UTR alignments, and this obser- 


\section{MAKAłOWSKI ET AL.}

vation is consistent with previous results on the size distributions of untranslated regions from human mRNAs (Pesole et al. 1994).

The average aligned identity of human/ mouse $5^{\prime}$ UTRs is $67.47 \%(\mathrm{SD}=13.2)$, and the average aligned identity of human/mouse $3^{\prime}$ UTRs was similar at $69.13 \%(S D=12.4)$. For both $5^{\prime}$ and 3' UTRs, the degrees of sequence conservation were distributed broadly between $30-40 \%$ and 100\% identity (Fig. 1A,D; Fig. 2).

The 1196 CDSs consisted of 1,733,644 nucleotides. Alignment lengths ranged in size from 135 to 13,638 nucleotides with a mean value of 1450 nucleotides ( $S D=1194$ ). The corresponding encoded proteins had alignment lengths from 44 to 4545 amino acids with a mean and SD of 481 and 397 residues, respectively. The ratio of average nucleotide-alignment-length to average protein-alignment-length is $\sim 3$, as it should be, given the triplet nature of the genetic code. The distributions of CDS and protein sizes are quite narrow (Fig. 1B,C). At least $50 \%$ of aligned CDSs fall between 758 and 1767 nucleotides, and $90 \%$ are $<2669$ nucleotides in length. For aligned proteins, $50 \%$ are in the range of 249 and 587 amino acid residues, and $90 \%$ are $<876$ residues in length. Outlying values in these size distributions include the sequences of the human

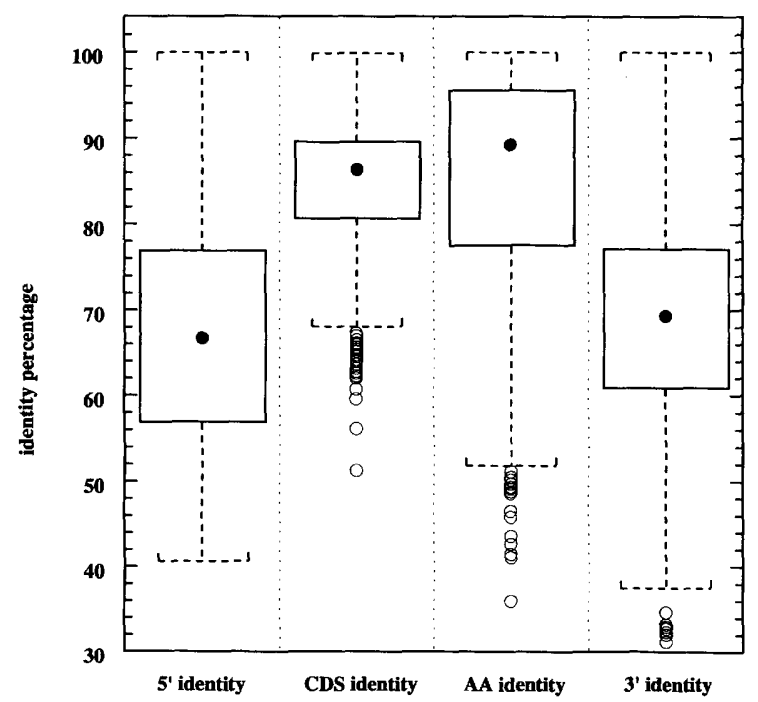

Figure 2 Box plots of aligned sequence identity distributions. For each category, the central box depicts the middle half of the data between the 25th and 75th percentiles; the black dots indicate the medians of each distribution. Extreme values in each distribution are indicated by the circles which fall outside the main body of data.
LDL receptor-related mRNA/protein $(14,896$ bases, 4544 residues; GenBank accession no. $\mathrm{X} 13916)$, human heparin sulfate proteoglycan $(14,327$ bases, 4391 residues; GenBank accession no. M85289), and the Duchenne muscular dystrophy gene product, dystophin (13,957 bases, 3685 residues; GenBank accession no. M18533).

The average aligned identity of human/ mouse CDSs is $84.62 \%(\mathrm{SD}=6.78)$ and the averaged aligned identity of human/mouse proteins is very similar at $85.39 \%(\mathrm{SD}=12.62)$. Sequence conservation is distributed more narrowly for coding sequences compared with proteins (Figs. 2 and 3). Twenty-seven proteins were $100 \%$ identical in sequence between humans and mice (Table 1). At the other extreme, some human/ mouse protein pairs were as little as $36-41 \%$ identical (Table 2).

\section{Biological and Evolutionary Aspects}

Although the $5^{\prime}$ and $3^{\prime}$ untranslated regions of

A

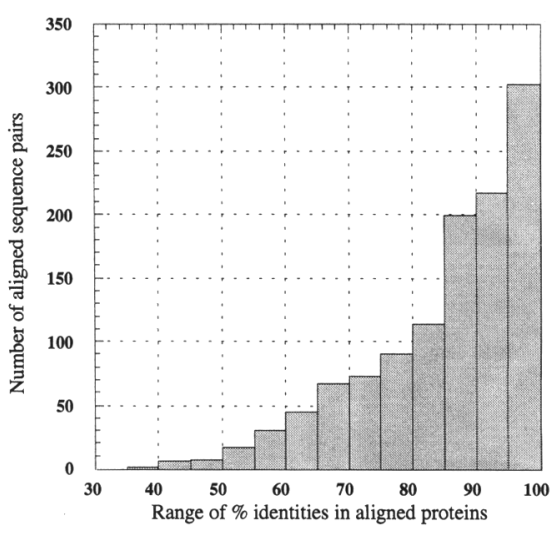

B

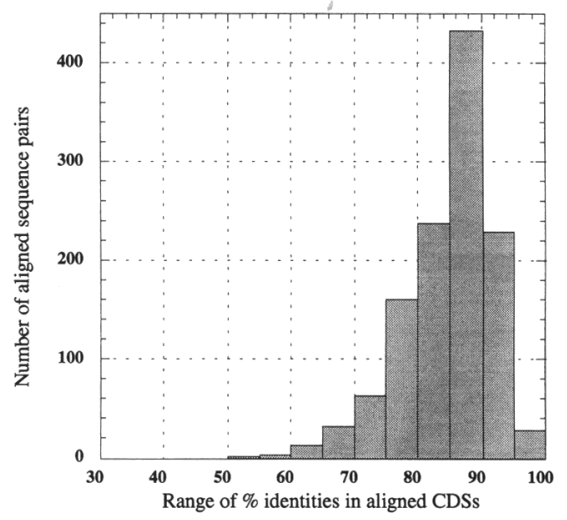

Figure 3 Distributions of sequence conservation in aligned mRNA coding sequences and the proteins they encode. 
Table 1. Human and Mouse Proteins with Identical Amino Acid Sequences

\begin{tabular}{|c|c|c|c|c|}
\hline Protein name $^{a}$ & $\begin{array}{l}\text { Human seq. } \\
\text { acc. number }\end{array}$ & $\begin{array}{l}\text { Mouse seq. } \\
\text { acc. number }\end{array}$ & $\begin{array}{l}\text { CDS } \\
\text { length }^{b}\end{array}$ & $\begin{array}{l}\text { CDS } \\
\text { identity } \\
(\%)^{c}\end{array}$ \\
\hline BTG1 & X61123 & L16846 & 516 & 96.71 \\
\hline Calmodulin & M19311 & $\times 61432$ & 450 & 84.01 \\
\hline DNA-binding protein (insulinoma rig-analog) & J02984 & M33330 & 438 & 89.95 \\
\hline Enteric smooth muscle gamma-actin & $\times 16940$ & M26689 & 1131 & 92.48 \\
\hline F-actin capping protein beta subunit & U03271 & U10407 & 819 & 92.67 \\
\hline GTP-binding protein (RAB1) & M28209 & Y00094 & 618 & 95.47 \\
\hline GTP-binding protein G25K & M57298 & L11318 & 573 & 95.64 \\
\hline GTP-binding protein (rac) & M29870 & $\times 57277$ & 579 & 91.36 \\
\hline Histone $\mathrm{H}_{3}$ & X00090 & $\times 16496$ & 411 & 86.13 \\
\hline Histone $\mathrm{H} 4$ (human gene $\mathrm{H} 4 / \mathrm{e}$ ) & X60484 & $\times 13235$ & 312 & 89.74 \\
\hline Histone H4 (human gene H4F2) & M16707 & V00753 & 312 & 87.50 \\
\hline Lupus autoantigen (snRNP) & j04615 & $X 62648$ & 723 & 91.15 \\
\hline MHC protein hom. to chicken B complex prot. & M24194 & X75313 & 954 & 90.57 \\
\hline Myelin proteolipid protein & M17085 & M15442 & 729 & 96.84 \\
\hline Nerve-terminal protein (isoform SNAP-25b) & L19761 & M22012 & 621 & 94.69 \\
\hline Nucleic acid binding protein-hnRNP-E2 & $X 78136$ & L19661 & 1086 & 97.61 \\
\hline Phosvitin/casein kinase II beta subunit & $\times 16312$ & $\times 56502$ & 648 & 93.67 \\
\hline PPP1CB & X80910 & M27073 & 984 & 94.61 \\
\hline Pre-mRNA splicing factor (SRp20) & $\mathrm{L} 10838$ & $\times 53824$ & 495 & 91.92 \\
\hline Ribosomal protein L30 & X79238 & K02928 & 348 & 93.97 \\
\hline Ribosomal protein L32 & X03342 & K02060 & 408 & 91.42 \\
\hline Ribosomal protein L37a & L06499 & X73331 & 279 & 90.68 \\
\hline Ribosomal protein S4 & M58459 & M73436 & 792 & 91.04 \\
\hline Ribosomal protein S8 & $\times 67247$ & X73829 & 627 & 89.79 \\
\hline Ribosomal protein S24 & D31520 & X60289 & 393 & 89.06 \\
\hline Ribosomal protein S28 & L05091 & U11248 & 210 & 87.62 \\
\hline Skeletal muscle alpha-actin & 100068 & M12866 & 1134 & 90.74 \\
\hline Thymosin beta- 4 & M17733 & $\times 16053$ & 135 & 93.33 \\
\hline
\end{tabular}

eukaryotic mRNAs have important biological functions (Jackson 1993; Gray and Hentze 1994; Decker and Parker 1995) it has been known for some time that their sequences are under less selective pressure than sequences that encode proteins (Nei 1987; Li and Graur 1991). In our data set, the $5^{\prime}$ and $3^{\prime}$ UTRs are 31-33\% divergent between human and mouse, whereas CDSs show only an $\sim 15 \%$ difference in aligned nucleotide identity (Fig. 2). The degree of sequence divergence was essentially identical (15\%) for CDSs and the proteins they encode (Fig. 2). This was somewhat surprising given the usual assumption that the detection of homology is much more sensitive using protein sequences rather than their cognate mRNAs (Doolittle 1981). Although this assumption is certainly true in the context of homologous genes from very distantly related organisms (e.g., humans and yeast; Tugendreich et al. 1994), it may not be true for mammalian species that shared a common ancestor only 80-100 million years ago.

Even though the mean values of sequence conservation of CDSs and proteins are nearly identical, the aligned amino acid identities show considerably greater variance $\left(\sigma^{2}=159\right)$ than aligned nucleotide identities $\left(\sigma^{2}=46\right)$ (Figs. 2 and 3). Also, the distribution of aligned amino acid identities is skewed toward higher values with a large number between 95\% and 100\% identity (Fig. 3). In contrast, the distribution of aligned nucleotide identities shows very few 
Table 2. The $\mathbf{2 5}$ Most Divergent Human and Mouse Proteins

\begin{tabular}{|c|c|c|c|c|c|c|}
\hline Protein name & $\begin{array}{l}\text { Human seq. } \\
\text { acc. number }\end{array}$ & $\begin{array}{l}\text { Mouse seq. } \\
\text { acc. number }\end{array}$ & $\begin{array}{l}5^{\prime} \text { UTR } \\
\text { identity } \\
(\%)\end{array}$ & $\begin{array}{l}\text { CDS } \\
\text { identity } \\
(\%)\end{array}$ & $\begin{array}{l}\text { Protein } \\
\text { identity } \\
(\%)\end{array}$ & $\begin{array}{l}\text { 3' UTR } \\
\text { identity } \\
(\%)\end{array}$ \\
\hline \multicolumn{7}{|l|}{ Alpha1-acid glycoprotein } \\
\hline \multicolumn{7}{|l|}{ B lymphocyte activation } \\
\hline antigen B7 (Ig) & M27533 & $\mathrm{X} 60958$ & 63.88 & 60.74 & 41.11 & 55.38 \\
\hline brk/Srm tyrosine kinase & X78549 & D26186 & 50.00 & 55.76 & 46.40 & 50.25 \\
\hline \multicolumn{7}{|l|}{ Centromere protein $C$} \\
\hline (CENP-C) & M95724 & U03113 & 61.81 & 70.95 & 52.44 & 77.36 \\
\hline CTLA4 counter receptor & U04343 & L25606 & 52.43 & 64.25 & 49.20 & 51.44 \\
\hline Fas (APO-1) & X63717 & M83649 & 54.72 & 66.46 & 49.54 & 61.47 \\
\hline Interferon beta & M28622 & $\times 14455$ & 65.71 & 68.98 & 50.00 & 66.83 \\
\hline Interferon gamma receptor & 103143 & M28995 & 55.26 & 68.60 & 52.26 & 55.14 \\
\hline \multicolumn{7}{|l|}{ Interferon-gamma induced } \\
\hline protein & M63838 & M31419 & 67.92 & 67.77 & $\begin{array}{l}49.30 \\
41.43\end{array}$ & $\begin{array}{l}66.11 \\
74.03\end{array}$ \\
\hline Interleukin 6 & X04430 & j03783 & 76.83 & 61.77 & 41.43 & 74.03 \\
\hline Interleukin 4 & M13982 & M25892 & 77.53 & 51.31 & 43.57 & 84.85 \\
\hline Interleukin 6 receptor & $\times 12830$ & $\times 53802$ & 55.48 & 69.99 & 53.17 & 62.18 \\
\hline Interleukin-4 receptor & $\times 52425$ & M27959 & 51.43 & 66.49 & 52.36 & 59.29 \\
\hline Kappa casein & M73628 & M10114 & 77.78 & 63.45 & 36.10 & 71.76 \\
\hline Leukosialin (sioalophorin) & j04168 & S70677 & & 62.03 & 48.96 & 50.76 \\
\hline NKR-P1A (lectin superfamily) & U11276 & M77677 & 57.78 & 63.23 & 46.40 & \\
\hline Olfactory receptor & X64995 & M84005 & & 56.10 & 42.72 & \\
\hline \multicolumn{7}{|l|}{ Prolactin-inducible protein } \\
\hline (PIP) & 103460 & 102510 & & 59.54 & 45.83 & \\
\hline Proteoglycan core protein & $\mathrm{X} 17042$ & $X 16133$ & 58.33 & 69.78 & 50.30 & 67.76 \\
\hline \multicolumn{6}{|l|}{ RNA polymerase I-specific } & 48.20 \\
\hline \multicolumn{7}{|l|}{ Sry (sex determining region } \\
\hline of Y-chromosome) & L08063 & U03645 & & 64.89 & 41.61 & \\
\hline T-cell glycoprotein Lyt-3 & $\times 13445$ & M17534 & 45.28 & 70.72 & 52.40 & 51.10 \\
\hline \multicolumn{7}{|l|}{ T-lymphocyte surface CD2 } \\
\hline (T11) antigen & M14362 & M18934 & & 68.44 & 52.34 & 68.75 \\
\hline Tcp-10 & U03399 & $\times 58170$ & 62.34 & 64.55 & 50.92 & 34.32 \\
\hline \multicolumn{7}{|l|}{$\begin{array}{l}\text { Tissue factor-membrane } \\
\text { protein that initiates the }\end{array}$} \\
\hline blood clotting & 102931 & M26071 & 87.68 & 68.17 & 51.04 & 71.15 \\
\hline
\end{tabular}

cases in the $95-100 \%$ range, but there is an obvious peak between $85 \%$ and $90 \%$ identity. We interpret these differences in the shapes and spreads of the distributions as a reflection of the rapid accumulation of nucleotide changes in synonymous (third base) codon sites followed by a slower mutation rate in nonsynonymous sites $(\mathrm{Li}$ and Graur 1991). Wolfe and Sharp (1993) have examined this phenomenon in a sample of 363 orthologous mouse and rat genes with the interesting finding that, in CDSs encoding less well- conserved proteins, aligned nucleotide identities exceeded aligned amino acid identities and that the "cross-over point" was $\sim 93 \%$. In our data set of mouse and human genes, the cross-over point lies at $84-85 \%$ (Fig. 4). This lower level undoubtedly reflects the more ancient divergence time of humans and mice ( 80 million years ago; Novacek 1992) compared with mice and rats, which diverged only 15 million years ago (Flynn et al. 1985).

To determine if any interesting biological de- 


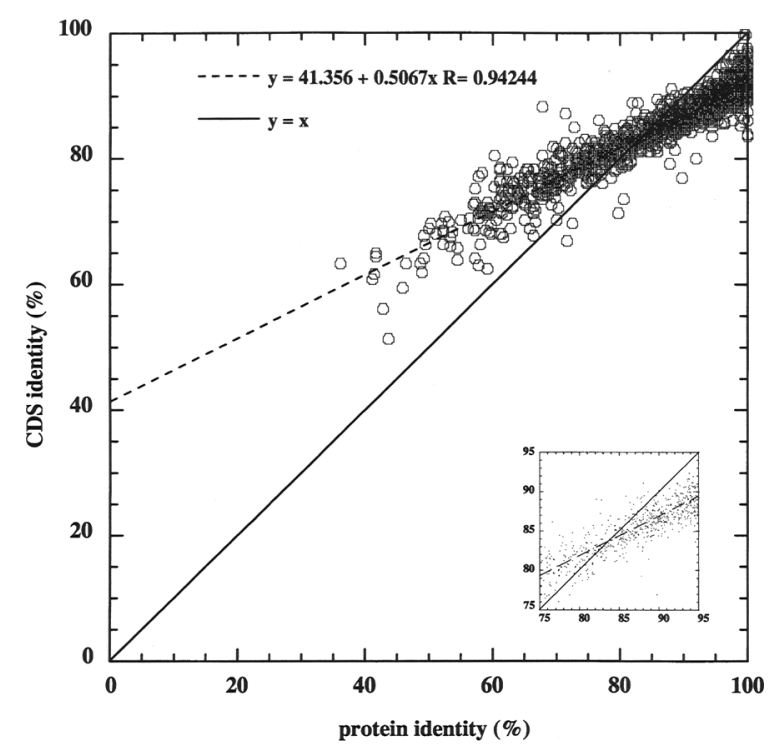

Figure 4 Scatter plot of protein vs. nucleotide sequence conservation. The dashed line represents a linear regression model of the data. The solid line allows the estimation of the crossover point between nucleotide and protein sequence identity. This is seen more easily in the inserted plot, which shows a more detailed picture of this region.

tails of protein function or evolution lay hidden in the distribution of aligned sequence identities, we considered various subsets of the mouse/ human sequence pairs. First, we examined extreme values at the upper and lower tails of the distribution. There were 27 proteins that were identical in sequence between human and mouse (Table 1) and these include several well-known cases of very slowly evolving genes, for example, actins and histones $\mathrm{H} 3$ and $\mathrm{H} 4$ ( Nei 1987; $\mathrm{Li}$ and Graur 1991). Also, a number of ribosomal proteins are conserved $100 \%$, presumably because the ribosome is a complex structure of interacting proteins where even small alterations in protein conformation are not tolerated. Several raslike GTPases, a variety of other signal transduction proteins, and some DNA- and RNA-binding proteins are also evident in this list.

The 25 least-conserved proteins range from $36 \%$ to $52 \%$ identical and are shown in Table 2 . It is interesting to note that for several cases, the $5^{\prime}$ and 3' UTRs are more highly conserved than the coding sequences. As to the biological nature of these 25 least-conserved proteins, Murphy (1993) has pointed out previously that proteins involved in antimicrobial host defenses (e.g., interleukins, interferons) are among the most diver- gent of proteins, and several examples of such are present in our sample (Table 2). Interferons have been noted independently to be very rapidly evolving proteins ( $\mathrm{Li}$ and Graur 1991). In the original papers describing 19 of these 25 proteins, the similarity between the mouse and human sequences was explicitly discussed, and in five cases the authors describe the similarity as high (Yokota et al. 1986; Murphy et al. 1987; Gubbay et al. 1990; Watanabe-Fukunaga et al. 1992; McKay et al. 1994); in only a single case was the similarity (appropriately) described as low (Munro and Maniatis 1989).

Two important questions about sequence pairs at the least-conserved end of our identity distribution are: (1) How can we be sure that these are true orthologs given the low degree of aligned identity; and (2) how can we be sure that this sample is representative of the spectrum of protein conservation between the mouse and human genomes as a whole? Regarding the first question, protein pairs were selected carefully in the context of sequence phylogenies where orthologous genes can be distinguished from paralogous genes. In some cases homology of synteny can be involved to support the claim (see below). Regarding the second question, has our data set been subject to ascertainment bias resulting from technical aspects involved in the original cloning of the genes? For example, if a human gene is cloned first and we are seeking the corresponding mouse gene by hybridization screening (or vice versa), are we likely to isolate only genes that are relatively well-conserved and, thus, bias the data away from more divergent orthologs? To address this question, we examined the original cloning papers and found that 12 out of the 25 most-diverged mRNA sequences (Table 2) were isolated and sequenced in independent projects and noted to be orthologous only after the fact. In 12 of the remaining cases, human or mouse cDNA libraries were screened using a sequence from the other species as a probe, and in the last case, a rat sequence was used to identify both the mouse and human genes. In four cases, the orthologous nature of the sequences was confirmed by syntenic human/mouse mapping data (Davies and Willson 1991; Goirda and Trucco 1991; Saitoh et al. 1992; Behlke et al. 1993; Islam et al. 1993; Coward et al. 1994; Lanier et al. 1994; McKay et al. 1994).

Rates of nucleotide substitution in fourfold degenerate sites in human and rodent coding sequences are $\sim 3.33$ substitutions per site per $10^{9}$ 
Table 3. Similarities between Human Inherited Disease Genes Identified by Positional Cloning and Their Mouse Ortholog $s^{a}$

\begin{tabular}{|c|c|c|c|c|c|c|}
\hline Disease & $\begin{array}{l}\text { Gene } \\
\text { symbol }\end{array}$ & Gene product & $\begin{array}{l}\text { Human } \\
\text { seq. acc. } \\
\text { number }\end{array}$ & $\begin{array}{l}\text { Mouse } \\
\text { seq. acc. } \\
\text { number }\end{array}$ & $\begin{array}{l}\text { CDS } \\
\text { identity } \\
(\%)\end{array}$ & $\begin{array}{l}\text { Protein } \\
\text { identity } \\
(\%) \\
\end{array}$ \\
\hline Aarskog-Scott syndrome & FGD1 & rho/rac GEF & U11690 & U22325 & 91.7 & 93.8 \\
\hline Achondroplasia & FGFLR & $\begin{array}{l}\text { fibroblast growth } \\
\text { factor receptor-3 }\end{array}$ & M58051 & S56291 & 85.7 & 93.4 \\
\hline $\begin{array}{l}\text { Adenomatous polyposis } \\
\text { coli }\end{array}$ & APC & & M74088 & M88127 & 87.6 & 90.6 \\
\hline $\begin{array}{l}\text { Amyotrophic lateral } \\
\text { sclerosis }\end{array}$ & SOD1 & $\begin{array}{l}\text { Cu-Zn superoxide } \\
\text { dismutase }\end{array}$ & X02317 & M35725 & 83.9 & 83.8 \\
\hline Aniridia & PAX6 & oculorhombin & M77844 & M77842 & 92.9 & 99.3 \\
\hline Breast cancer type 1 & BRCA1 & & U14680 & U32446 & 75.2 & 57.2 \\
\hline $\begin{array}{l}\text { Chronic granulomatous } \\
\text { disease }\end{array}$ & NCF1 & $\begin{array}{l}\text { neutrophil cytosol } \\
\text { factor } 1\end{array}$ & M55067 & L11455 & 80.9 & 81.7 \\
\hline $\begin{array}{l}\text { Congenital adrenal } \\
\text { hyperplasia }\end{array}$ & CYP21 & $\begin{array}{l}\text { steroid } 21 \text {-mono- } \\
\text { oxygenase }\end{array}$ & M26856 & M15009 & 77.4 & 72.4 \\
\hline Cystic fibrosis & CFTR & $\begin{array}{l}\text { transmembrane } \\
\text { conductance } \\
\text { regulator }\end{array}$ & M28668 & M69298 & 81.4 & 78.5 \\
\hline Diastrophic dysplasia & DTD & $\begin{array}{l}\text { sulfate trans- } \\
\text { porter }\end{array}$ & U14528 & D42049 & 83.4 & 80.9 \\
\hline $\begin{array}{l}\text { Duchenne muscular } \\
\text { dystrophy }\end{array}$ & DMD & dystrophin & M18533 & M18025 & 87.8 & 86.9 \\
\hline Fragile- $X$ syndrome & FMR1 & & S65791 & L23971 & 95.7 & 96.6 \\
\hline $\begin{array}{l}\text { Glycerol kinase } \\
\text { deficiency }\end{array}$ & GK & glycerol kinase & L13943 & D16102 & 91.7 & 97.3 \\
\hline Gonadal dysgenesis & SRY & $\begin{array}{l}\text { testis-determining } \\
\text { factor }\end{array}$ & L08063 & U03645 & 64.9 & 41.6 \\
\hline $\begin{array}{l}\text { Hereditary non-polyposis } \\
\text { colon cancer }\end{array}$ & hPMS2 & $\begin{array}{l}\text { DNA mismatch } \\
\text { repair enzyme }\end{array}$ & U14658 & U28724 & 80.8 & 73.4 \\
\hline $\begin{array}{l}\text { Hereditary non-polyposis } \\
\text { colon cancer }\end{array}$ & hMSH2 & $\begin{array}{l}\text { DNA mismatch } \\
\text { repair enzyme }\end{array}$ & U04045 & $\times 81143$ & 86.7 & 92.5 \\
\hline Huntington's disease & HD & huntingtin & L12392 & L28827 & 86.4 & 91.18 \\
\hline Hyperexplexia & GLYR A2 & $\begin{array}{l}\text { inhibitory glycine } \\
\text { receptor }\end{array}$ & $\times 52009$ & S73717 & 90.5 & 97.8 \\
\hline Menkes disease & MNK & $\begin{array}{l}\text { heavy metal } \\
\text { binding protein }\end{array}$ & X69208 & U03434 & 85.7 & 84.4 \\
\hline Miller-Dieker lissencephaly & PAF & $\begin{array}{l}\text { acetylhydrolase } \\
\text { subunit }\end{array}$ & L13385 & L34659 & 95.2 & 99.76 \\
\hline $\begin{array}{l}\text { Multiple endocrine } \\
\text { neoplasia } 2 \mathrm{~A}\end{array}$ & RET & $\begin{array}{l}\text { receptor tyrosine } \\
\text { kinase }\end{array}$ & M57464 & X67812 & 84.1 & 85.3 \\
\hline Myotonic dystrophy & DM & $\begin{array}{l}\text { mutonin protein } \\
\text { kinase }\end{array}$ & L19268 & Z21503 & 83.1 & 83.6 \\
\hline Neurofibromatosis type 1 & NF1 & neurofibromin & M89914 & $\times 54924$ & 91.5 & 99.5 \\
\hline Neurofibromatosis type 2 & NF2 & merlin & L11353 & L27090 & 90.0 & 98.5 \\
\hline Norrie disease & NDP & & X65882 & X83794 & 91.9 & 95.4 \\
\hline Retinoblastoma & RB1 & & M15400 & M26391 & 88.6 & 89.6 \\
\hline Thomsen disease & $\mathrm{CLC1}$ & $\begin{array}{l}\text { skeletal muscle } \\
\text { chloride channel }\end{array}$ & Z25884 & $\mathrm{X} 62896^{\mathrm{b}}$ & 88.4 & 91.5 \\
\hline $\begin{array}{l}\text { vonHippel-Lindau } \\
\text { syndrome }\end{array}$ & VHL & & $\mathrm{L}^{15409^{\mathrm{b}}}$ & U12570 & 84.4 & 90.1 \\
\hline
\end{tabular}


Table 3. (Continued)

\begin{tabular}{|c|c|c|c|c|c|c|}
\hline Disease & $\begin{array}{l}\text { Gene } \\
\text { symbol }\end{array}$ & Gene product & $\begin{array}{l}\text { Human } \\
\text { seq. acc. } \\
\text { number }\end{array}$ & $\begin{array}{l}\text { Mouse } \\
\text { seq. acc. } \\
\text { number }\end{array}$ & $\begin{array}{l}\text { CDS } \\
\text { identity } \\
(\%)\end{array}$ & $\begin{array}{l}\text { Protein } \\
\text { identity } \\
\text { (\%) }\end{array}$ \\
\hline Waardenburg syndrome & PAX3 & $\begin{array}{l}\text { paired box homeo- } \\
\text { domain protein }\end{array}$ & U02309 & $\times 59358$ & 91.5 & 97.9 \\
\hline Wilms tumor & WT1 & zinc-finger protein & $\times 51630$ & M55512 & 90.8 & 96.7 \\
\hline Wilson disease & WND & $\begin{array}{l}\text { copper-transporting } \\
\text { ATPase }\end{array}$ & U03464 & U38477 & 66.3 & 57.4 \\
\hline $\begin{array}{l}\text { X-linked adrenoleuko- } \\
\text { dystrophy }\end{array}$ & ALD & & Z21876 & Z33637 & 86.1 & 91.4 \\
\hline
\end{tabular}

years (Li and Graur 1991), or 0.53 substitutions per site over the elapsed time since the mammalian radiation, $\sim 80$ million years ago. Applying the Jukes and Cantor (1969) model to correct for multiple substitutions, the observed divergence is expected to be 0.38 . It follows that, in the absence of selective pressure, the most divergent mouse and human DNA sequences should be $62 \%$ conserved ( $38 \%$ diverged). The fact that we have some values even lower than this in our data set (Fig. 4 and Table 2) suggests that we do indeed have an adequate sample of the most divergent mouse and human protein pairs.

A definitive answer to the question of how representative is the data at the lower end of the distribution may have to await the acquisition of large amounts of syntenic human and mouse genomic sequence in which random samples of protein-coding genes are fourd. Current samples of orthologous human and rodent genomic DNA have shed some light on patterns of conservation in noncoding sequences (Koop and Hood 1994), but have not yet extended our knowledge of rapidly evolving sequences that encode proteins. However, we can extrapolate the lower level of detectable orthology from a consideration of mutation rates in fourfold degenerate codon sites $(\mathrm{Li}$ and Graur 1991) and also from a linear regression analysis of our nucleotide and amino acid alignment data (Fig. 4).

Another interesting conclusion from our data is that, if we extrapolate to even lower degrees of sequence identity than those present in our sample of aligned sequences, we can see that at the level of $40 \%$ identity between mouse and human CDSs, no identical residues at all are expected in the protein alignments (Fig. 4). Of course, this is an oversimplified view of protein evolution, and, in practice, amino acid substitution matrices are used to detect distant similarities and assess their significance (Henikoff and Henikoff 1993). As a point of reference, even the most distantly related sequence pair in our study (kappa casein; Table 2) yields unquestionably significant similarities between the mouse and human orthologs in the context of a data-base search using the default (BLOSUM62) scoring matrix $($ BLASTN score $=665 ; p$ value $=5.9 \times$ $10^{-58} ;$ BLASTP score $=231 ; p$ value $=1.9 \times$ $\left.10^{-33}\right)$.

To date, there have been $>60$ human disease genes isolated by positional cloning (Bassett et al. 1996). We have found that in 32 cases the orthologous mouse sequence is available also (Table 3). In many ways, the properties of these sequences recapitulate the characteristics of our larger mouse/human collection. They range in size from small, globular enzymes such as superoxide dismutase (153 residues) up to the 3785residue structural protein, dystrophin. Whereas the mean values of sequence conservation for DNA and protein alignments in our large set of mouse/human homologs are $84.62 \%$ and $85.39 \%$ identity, respectively, the mean values of sequence conservation for the disease gene coding sequences and proteins are very similar at $86.0 \%$ and $87.1 \%$, respectively. Because these disease genes were cloned based solely by map position, and yet are so similar in sequence properties to our larger, 1196-sequence sample, this supports 


\section{MAKALOWSKI ET AL.}

our contention that the latter sample is not subject to serious ascertainment bias based on technical aspects of functional cloning.

Last, the list of disease genes contains several outliers with respect to sequence conservation. These include the breast cancer (BRCA1) gene product $(57.2 \%$ identical) and the coppertransporting ATPase that is the product of the Wilson disease gene (57.4\% identical). The testisdetermining factor, $S R Y$, is even more divergent (41.6\% identical between mouse and human). In our data set of 1196 proteins, only kappa casein (Table 2) is more divergent than the $S R Y$ gene product. Rapid sequence divergence may be important for the function of these proteins.

\section{Introns and Interspersed Repeats}

We have examined our data set for the occurrence of introns and repetitive elements. Such information has practical implications for gene mapping (Wilcox et al. 1991) and cloning (Yulug et al. 1995).

To determine the relative frequency of introns in $5^{\prime}$ and $3^{\prime}$ UTRs, we performed a text query search of sequence feature annotations in GenBank records. Also, BLASTN searches were done using $5^{\prime}$ and $3^{\prime}$ UTR sequences from our data set as queries against a genomic sequence subset of the primate and rodent divisions of GenBank. In our data set, 954 mRNAs had 5' UTR sequence in either mouse or human sequence records. Among these, $585^{\prime}$ UTRs contained one or two introns, although there are two human mRNA sequences with as many as four introns annotated in the GenBank record (accession nos. U19251 and L22214). In our data set, 1077 mRNAs had 3' UTR sequences and only seven of them had one or two introns. In all but one of these cases the presence of the 3' UTR intron was confirmed by the comparison of the mRNA sequences with the genomic one. Thus, introns are about nine times less likely to be found in $3^{\prime}$ UTRs compared with 5' UTRs. We cannot determine the absolute frequencies of introns in untranslated regions from these data because corresponding genomic sequence data exists for only a fraction of the mRNA sequences in our collection.

In the $3^{\prime}$ UTRs, introns usually are close to the stop codon. The closest intron is in position $13 / 14$ at the human growth hormone-dependent, insulin-like growth factor-binding protein mRNA (GenBank accession no. M31159). The most distant intron is located at position $89 / 90$ of the human antigen CD36 3' UTR (GenBank accession no. M98399).

Previously, Yulug et al. (1995) have studied the frequency and positions of Alu repeats in a large collection of human mRNAs and found them to be present in 5\% of fully spliced sequences, with the majority of cases occurring in the 3' UTR. Our analysis includes mouse as well as human mRNAs and a more extensive collection of different types of repeats.

The most abundant group of mammalian repeats are short interspersed repetitive elements (SINEs), and members of this group are found most frequently in our collection of sequences. We found 67 Alu sequences in 57 human $3^{\prime}$ UTRs, or in $5.7 \%$ of the $10773^{\prime}$ UTRs in our data set (a frequency similar to that observed by Yulug et al. 1995). Our human 3' UTR sequences also contained 18 mammalian-wide interspersed repeats (MIRs), three fragments of L1 [long interspersed repeated sequences (LINE)] repetitive elements, seven different medium reiterated frequency repeats (MERs), four repeat fragments of retroviral origin, and one fragment of a transposon-like human DNA transposons related to the Drosophila transposon pogo (tigger) repeat (Jurka et al. 1992; Smit and Riggs 1996). Similarly, most of the repeats found in mouse 3' UTRs are SINEs: $42 \mathrm{~B} 1$ or B2 elements were observed. Additionally, we found five fragments of the mouse L1 retroposon and 21 fragments of other mouse retroelements. In summary, $91(8.5 \%)$ of human $3^{\prime}$ UTR sequences and $70(3.7 \%)$ of mouse $3^{\prime}$ UTR sequences showed evidence of some type of repetitive element.

In contrast, the frequency of repetitive elements in $5^{\prime}$ UTRs is much lower. In our set of 954 human $5^{\prime}$ UTRs, there were only $10 \mathrm{Alu}$, three L1 elements, four MIRs, and seven fragments of other transposon-like repeats. In mouse 5' UTRs only five $\mathrm{B} 1$ retroposons, one $\mathrm{B} 2$ element, and three fragments of other repeats were observed. Thus, repetitive elements are three to seven times more likely to be found in $3^{\prime}$ UTRs compared with 5' UTRs.

In one case, we observed MIR insertions at orthologous positions in the $3^{\prime}$ UTRs of both mouse and human interleukin-10 mRNAs. The elements are $65.4 \%$ identical and reside 1423 bases downstream of the stop codon in mice and 1570 bases downstream of the stop codon in humans. The IL-10 MIR element is a molecular fossil of a retrotransposition event that occurred $\sim 150$ 
million years ago (assuming a constant mutation rate, and an eutherian radiation date of 80 million years ago).

\section{Implications for the "Comparative Genomics" of Mice and Humans}

A complete description of the comparative genomics of two organisms would include pairwise sequence alignments of genomic DNA from all homologous regions among their chromosomes. We are a long way from that goal for humans and mice. Nevertheless, the human/mouse comparative map is quite extensive, currently containing 1416 loci in 181 conserved linkage groups (DeBry and Seldin 1996). Furthermore, a glimpse of comparative genomic structure, at the ultimate resolution of nucleotides, is available through a small number of sequence contigs that exist for both species (Koop 1995; Lamerdin et al. 1995). The present study supplements this information by providing an analysis of $\sim 1200$ functionally cloned, transcribed, protein-coding sequences. Here we have computed the simplest, most practical, and reproducible measure of sequence conservation, namely, percent identity after optimal alignment. Although we avoided using BLASTN $p$-values as a measure, because of their dependence on the size of the data base and scoring matrix used, the availability of our complete data set on the World Wide Web will allow anyone to compute the measure most suitable for their specific purposes. Currently, we are performing synonymous and nonsynonymous rate calculations on the coding sequences in our data set, and these results will be reported elsewhere.

Our results on the distributions and averages of pairwise sequence similarities between mouse and human mRNAs should prove useful in interpreting mouse cDNA sequencing data (Washington University and Howard Hughes Medical Institute 1996). One of the principle goals of this project is to supplement the human cDNA collection to produce a more comprehensive sample of mammalian genes. Thus, it will be very important, when aligning a mouse cDNA to a human gene, a human cDNA to a mouse gene, or human and mouse cDNAs to each other, to have some standard of comparison for distinguishing between orthologous sequences and paralogous sequences, that is, different members of a multigene family.

Using the alignment information produced in our study, it should also be possible to develop sequence-based mapping reagents that may be used for physical and genetic mapping in either species. Such reagents could extend the human/ mouse comparative map, but first it will be necessary to correlate our results, which are based upon sequence alignments, with results based upon other criteria (O'Brien and Graves 1991). Human/mouse homology maps, based upon these criteria, are available through the Mouse Genome Database at the Jackson Laboratory, Bar Harbor, ME (http://www.infomatics.jax.org/).

Finally, our collection of 1196 orthologous mouse and human genes might be useful as a standard for more extensive cross-referencing among other, more distantly related genomes such as those of nematodes and yeast (Bassett et al. 1995).

\section{METHODS}

Human and murine mRNA sequences were extracted from GenBank Release 87 (March 1995). Orthologous sequences were distinguished from paralogous sequences using the molecular phylogenies provided in the HOVERGEN data base of homologous vertebrate genes (Duret et al. 1994). Of the 3716 protein families in Release 11 of HOVERGEN, 1236 correspond to mRNA sequences with full-length coding regions available for both mouse and human species. Each of the 1236 phylogenetic trees was inspected and orthologous pairs of genes selected. This was a crucial step in assembling data appropriate for further study because some of the families contain subfamilies with different hu$\mathrm{man} /$ mouse orthologs and other families include fulllength human and mouse coding sequences but situated on different branches of a phylogenetic tree, indicating a paralogous origin of these sequences. Whenever a given protein was represented by several GenBank records, the longest possible mRNA sequence was chosen for the human/mouse comparison. This set of HOVERGEN-derived sequences was supplemented by $32 \mathrm{mRNA} /$ protein sequences corresponding to positionally cloned human disease genes (Table 3), that appeared subsequent to the release of HOVERGEN 11 and for which mouse homologs were available. These human/mouse pairs were identified through literature and homology searches.

In total, there were 1196 orthologous human/mouse mRNA pairs included in this study. A number of these mRNAs had either very short, or unknown, $5^{\prime}$ and $3^{\prime}$ UTRs. We excluded all $5^{\prime}$ UTRs $<20$ nucleotides and all $3^{\prime}$ UTRs $<40$ nucleotides from the study. Consequently, $8785^{\prime}$ UTRs and $9473^{\prime}$ UTRs met these minimum-length criteria.

Human and mouse mRNA and protein sequences were aligned using the sim 2 program (Chao et al. 1995) that, by sequence accession number, extracts sequence data directly from GenBank (Benson et al. 1996) using the Entrez application programming interface (ftp:// ncbi.nlm.nih.gov/toolbox/ncbi_tools). This assures that the most recent data always was used. The parsesim program (J. Zhang, unpubl.) was used for the extracting the different mRNA regions (coding and untranslated se- 


\section{MAKALOWSKI ET AL.}

quences) and protein sequences from ASN.1 files into the separate text files. The final alignments of both nucleotide and protein sequences were computed using the gap program that utilizes a global, optimal alignment algorithm (Huang 1994)

The entire set of human and mouse mRNA sequences was searched for different repetitive elements using the CENSOR program (Jurka et al. 1996). The program was run in the "conservative" mode against a reference collection of rodent or human repeats (Jurka 1995).

\section{ACKNOWLEDGMENTS}

We thank Dr. Jerzy Jurka for providing the CENSOR program.

The publication costs of this article were defrayed in part by payment of page charges. This article must therefore be hereby marked "advertisement" in accordance with 18 USC section 1734 solely to indicate this fact.

\section{REFERENCES}

Bassett, D., M. Boguski, F. Spencer, R. Reeves, M. Goebl, and P. Hieter. 1995. Comparative genomics, genome cross-referencing and XREFdb. Trends Genet.

11: $372-373$.

Bassett, D.E., M.S. Boguski, and P. Hieter. 1996. Yeast genes and human disease. Nature 379: 589-590.

Behlke, M.A., J.S. Bogan, P. Beer-Romero, and D.C. Page, 1993. Evidence that the SRY protein is encoded by a single exon on the human Y chromosome. Genomics 17: 736-739.

Benson, D.A., M. Boguski, D.J. Lipman, and J. Ostell. 1996. GenBank. Nucleic Acids Res. 24: 1-5.

Boguski, M.S. and G.D. Schuler. 1995. ESTablishing a human transcript map. Nature Genet. 10: 369-371.

Chao, K.M., J. Zhang, J. Ostell, and W. Miller. 1995. A local alignment tool for very long DNA sequences. Comput. Appl. Biosci. 11: 147-153.

Coward, P., K. Nagai, D. Chen, H.D. Thomas, C.M. Nagamine, and Y.F. Lau. 1994. Polymorphism of a CAG trinucleotide repeat within Sry correlates with B6.YDom sex reversal. Nature Genet. 6: 245-50.

Davies, P.O. and K.R. Willison. 1991. Sequence of the $t$ complex Tcp-10at gene and examination of the Tcp-10t gene family. Mamm. Genome 1: 235-241.

DeBry, R. and M. Seldin. 1996. Human/mouse homology relationships. Genomics 33: 337-351.

Decker, C. and R. Parker. 1995. Diversity of cytoplasmic functions for the 3' untranslated region of eukaryotic transcripts. Curr. Opin. Cell Biol. 7: 386-392.

Doolittle, R. 1981. Similar amino acid sequences: Chance or common ancestry? Science 214: 149-159.
Duret, L., D. Mouchiroud, and M. Gouy. 1994. HOVERGEN: A data base of homologous vertebrate genes. Nucleic Acids Res. 22: 2360-2365.

Flynn, L., L. Jacobs, and E. Lindsay. 1985. Problems in muroid phylogeny: Relationship to other rodents and origin of major groups. In Evolutionary relationships among rodents: A multidisciplinary analysis (ed. W. Luckett and J.-L. Hartenberger), pp. 589-616. Plenum Press, New York, NY.

Giorda, R. and M. Trucco. 1991. Mouse NKR-P1. A family of genes selectively coexpressed in adherent lymphokine-activated killer cells. I. Immunol.

147: 1701-1708.

Gray, N. and M. Hentze. 1994. Regulation of protein synthesis by mRNA structure. Mol. Biol. Reports 19: $195-200$.

Gubbay, J., J. Collignon, P. Koopman, B. Capel, A. Economou, A. Munsterberg, N. Vivian, P. Goodfellow, and R. Lovell-Badge. 1990. A gene mapping to the sex-determining region of the mouse $\mathrm{Y}$ chromosome is a member of a novel family of embryonically expressed genes. Nature 346: 245-250.

Henikoff, S. and J.G. Henikoff. 1993. Performance evaluation of amino acid substitution matrices. Proteins 17: 49-61.

Huang, X. 1994. On global sequence alignment. Comput. Appl. Biosci. 10: 227-235.

Islam, S.D., S.H. Pilder, C.L. Decker, J.A. Cebra-Thomas, and L.M. Silver. 1993. The human homolog of a candidate mouse $t$ complex responder gene: Conserved motifs and evolution with punctuated equilibria. Hum. Mol. Genet. 2: 2075-2079.

Jackson, R. 1993. Cytoplasmic regulation of mRNA function: The importance of the 3 ' untranslated region. Cell 74: 9-14.

Jukes, T.H. and C.R. Cantor. 1969. Evolution of protein molecules. In Mammalian protein metabolism (ed. H.N. Monro), pp. 21-132. Academic Press, New York, NY.

Jurka, J. 1995. Data base of repetitive elements (repbase). NCBI Database Repository. ftp: //ncbi.nlm.nih.gov/ repository/repbase.

Jurka, J., J. Walichiewicz, and A. Milosavljevic. 1992. Prototypic sequences for human repetitive DNA. J. Mol. Evol. 35: 286-291.

Jurka, J., P. Klonowski, V. Dagman, and P. Pelton. 1996. CENSOR: A program for identification and elimination of repetitive elements from DNA sequences. Computers and Chemistry 20: 119-122.

Koop, B. 1995. Human and rodent DNA sequence comparison: A mosaic model of genomic evolution. Trends Genet. 11: 367-371. 


\section{COMPARATIVE ANALYSIS OF MOUSE AND HUMAN ORTHOLOGS}

Koop, B.F. and L. Hood. 1994. Striking sequence similarity over almost 100 kilobases of human and mouse T-cell receptor DNA. Nature Genet. 7: 48-53.

Lamerdin, J.E., M.A. Montgomery, S.A. Stilwagen, L.K. Scheidecker, R.S. Tebbs, K.W. Brookman, L.H. Thompson, and A.V. Carrano. 1995. Genomic sequence comparison of the human and mouse XRCC1 DNA repair gene regions. Genomics 25: 547-554.

Lanier, L.L., C. Chang, and J.H. Phillips. 1994. Human NKR-P1A. A disulfide-linked homodimer of the C-type lectin superfamily expressed by a subset of $\mathrm{NK}$ and $\mathrm{T}$ lymphocytes. J. Immunol. 153: 2417-2428.

Li, W.-H. and D. Graur. 1991. Fundamentals of molecular evolution. Sinauer Associates, Sunderland, MA.

McKay, S., E. Thomson, and H. Cooke. 1994. Sequence homologies and linkage group conservation of the human and mouse Cenpc genes. Genomics 22: 36-40.

Munro, S. and T. Maniatis. 1989. Expression cloning of the murine interferon gamma receptor cDNA. Proc. Natl. Acad. Sci. 86: 9248-9252.

Murphy, L.C., D. Tsuyuki, Y. Myal, and R.P. Shiu. 1987. Isolation and sequencing of a cDNA clone for a prolactin-inducible protein (PIP). Regulation of PIP gene expression in the human breast cancer cell line, T-47D. J. Biol. Chem. 262: 15236-15241.

Murphy, P.M. 1993. Molecular mimicry and the generation of host defense protein diversity. Cell 72: 823-826.

Nei, M. 1987. Molecular evolutionary genetics. Columbia University Press, New York, NY.

Novacek, M.J. 1992. Mammalian phylogeny: Shaking the tree. Nature 356: 121-125.

O'Brien, S. and J.A. Graves. 1991. Report of the committee on comparative gene mapping. Cytogenet. Cell Genet. 58: 1124-1151.

Pesole, G., G. Fiormarino, and C. Saccone. 1994. Sequence analysis and compositional properties of untranslated regions of human mRNAs. Gene 140: $219-225$.

Saitoh, H., J. Tomkiel, C.A. Cooke, H.D. Ratrie, M. Maurer, N.F. Rothfield, and W.C. Earnshaw. 1992. CENP-C, an autoantigen in scleroderma, is a component of the human inner kinetochore plate. Cell 70: 115-125.

Smit, A. and A. Riggs. 1996. Tiggers and other DNA transposon fossils in the human genome. Proc. Natl. Acad. Sci. 93: 1443-1448.

Tugendreich, S., D.E. Bassett, V.A. McKusick, M.S. Boguski, and P. Hieter. 1994. Genes conserved in yeast and humans. Hum. Mol. Genet. 3: 1509-1517.
Washington University and Howard Hughes Medical Institute Mouse EST Project 1996. http://genome. wustl.edu/est/mouse_esthmpg.html.

Watanabe-Fukunaga, R., C.I. Brannan, N.G. Copeland, N.A. Jenkins, and S. Nagata. 1992. Lymphoproliferation disorder in mice explained by defects in Fas antigen that mediates apoptosis. Nature 356: 314-317.

Wilcox, A.S., A.S. Khan, J.A. Hopkins, and J.M. Sikela. 1991. Use of $3^{\prime}$ untranslated sequences of human cDNAs for rapid chromosome assignment and conversion to STSs: Implications for an expression map of the genome. Nucleic Acids Res. 19: 1837-1843.

Wolfe, K.H. and P.M. Sharp. 1993. Mammalian gene evolution: Nucleotide sequence divergence between mouse and rat. J. Mol. Evol. 37: 441-56.

Yokota, T., T. Otsuka, T. Mosmann, J. Banchereau, T. DeFrance, D. Blanchard, J.E. De Vries, F. Lee, and K. Arai. 1986. Isolation and characterization of a human interleukin cDNA clone, homologous to mouse B-cell stimulatory factor 1 , that expresses B-cell- and T-cell-stimulating activities. Proc. Natl. Acad. Sci. 83: $5894-5898$.

Yulug, I.G., A. Yulug, and E.M. Fisher. 1995. The frequency and position of Alu repeats in cDNAs, as determined by data base searching. Genomics 27: $544-548$.

Received May 22, 1996; accepted in revised form July 9, 1996. 


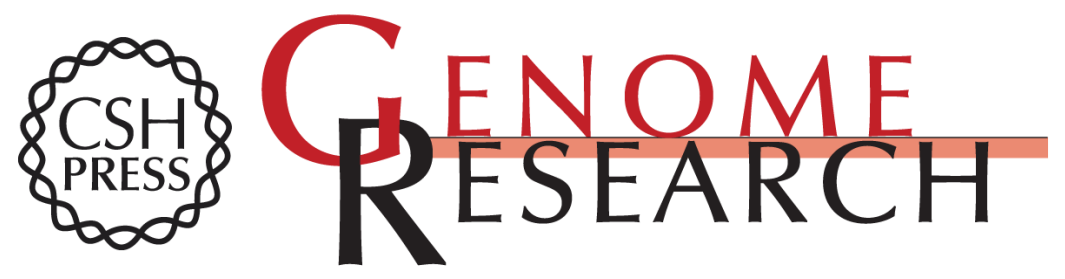

\section{Comparative analysis of 1196 orthologous mouse and human full-length mRNA and protein sequences.}

W Makalowski, J Zhang and M S Boguski

Genome Res. 1996 6: 846-857

Access the most recent version at doi:10.1101/gr.6.9.846

References This article cites 40 articles, 7 of which can be accessed free at:

http://genome.cshlp.org/content/6/9/846.full.html\#ref-list-1

\section{License}

Email Alerting Receive free email alerts when new articles cite this article - sign up in the box at the Service top right corner of the article or click here.

\section{Affordable, Accurate Sequencing.}

To subscribe to Genome Research go to:

https://genome.cshlp.org/subscriptions 